\title{
Developing and Validating an eHealth Communication Belief Inventory (eHealth-BI) among Chinese Middle- and Older-Age Adults
}

\author{
Su-I Hou ${ }^{1, *}$, Peng-Hsi Hou ${ }^{2}$ \\ ${ }^{1}$ Department of Health Promotion and Behavior, College of Public Health, The University of Georgia, Athens, GA, 30602, United \\ States ${ }^{2}$ Industrial Engineering and Management, The National Taipei University of Technology, Taiwan \\ *Corresponding Author: shou@uga.edu
}

Copyright @ 2013 Horizon Research Publishing All rights reserved.

\begin{abstract}
Purpose: As the world population rapidly aging, especially in Asia, and "the graying of the Internet", opportunities of eHealth communication among middleand older-age adults warrants more attention. Methods: The eHealth communication survey was administered to employee age $40+$ in two major worksites in Taiwan. The development and validation of a 7-item eHealth communication belief inventory (eHealth-BI) by age groups were examined. Results: A total of 533 employees participated (mean age $=46.21(\mathrm{SD}=5.01)$ years). The reliabilities of the eHealth-Pros (4-items) and the eHealth-Cons (3-items) measured by Cronbah alphas were satisfactory in both age groups (40-49 and 50-64 years), demonstrating sufficient internal consistencies among items. Confirmatory factor analysis showed that all items were loaded significantly on these two eHealth-BI sub-scales with good model fits. Males and those with college education overall were more likely to perceive higher benefits and lower barriers towards eHealth communication. Conclusion: Findings provide needed validation on this new theory-based bi-lingual eHealth-BI tool. Results provide health researchers and practitioners an important tool to measure beliefs towards eHealth communication for better understanding of system design needs, and for effective eHealth communication intervention development among middle- and older-age Chinese adults.
\end{abstract}

Keywords eHealth Communication, Belief Inventory, Instrument Validation, Middle- and Older-Age Adults, Workplace, Taiwan

\section{Introduction}

Health promotion efforts that are mediated by computer and the Internet have great potential to promote desired behavioral health outcomes. The hybrid features of interpersonal and mass communication make the Internet an ideal place for the application of key social and behavioral science theories to promote healthier behaviors. Neuhauser and Kreps [1] reviewed the first 15 years of eHealth studies and suggest that eHealth intervention strategies have not only gained rapid acceptance worldwide, but also have shown significant positive changes on health behaviors across health conditions and in diverse population. As we enter the rapidly changing eHealth era, we need to rethink how to leverage the power of the Internet and media while we continue improving access and acceptability to bridge the digital divide for the vulnerable groups.

\section{The Increased OHI Utilization \& the Graying of the Internet}

The Pew Internet Study has shown a steady prevalence of about 8 in 10 U.S. Internet users who have looked online for health information [2]. Internet use as more of a technological facet of the younger generation is a common misperception among many. A comparison of the populations who used the Internet for health information showed that both the percentages of older adults and that of adolescents who utilized online health information were very similar [3]. In a recent Pew Internet Study examines U.S. older adults, findings show that overall about $90 \%$ of the participants age 50 and older send or read emails, and majority of them exchange email messages on a typical day [4]. In addition, data show that among a representative sample of U.S. adults, over half of the Internet users age 50-64 years use social networking sites [5]. As the world population rapidly aging and "the graying of the Internet", opportunities of eHealth communication and interventions among middle- and older-age adults warrants more attention [2-5].

\section{Patients Trust Doctors but Consult the Internet}

Although consulting face-to-face with health professionals and providers continues to be a first line of action for dealing with health issues, significant portions of older adults also seek out online health information or 
participate in the online health community [6-7]. Recent HINTS data [8] show that the two most frequently used sources of cancer information was the Internet $(55.3 \%)$, followed by health care providers $(24.9 \%)$. Across the spectrum of age, sex and Internet skill, studies show that online health information seeking appears to enhance the patient-provider relationship [3,9].

\section{Beliefs towards eHealth Communication}

There is a paucity of research in examining attitudes or beliefs towards Internet health communication among Chinese adults. Previous studies identify that learner's fear of technology and insufficient computer skills influence their views towards online learning [10]. There have been few studies examining online health information seeking information in Asian countries. Yu and Yang [11] are among the first to examine attitudes and intentions towards web-based learning among public health nurses in Taiwan [11-12]. Despite increased Internet utilization among middle- and older-age adults, little is known about perceptions or beliefs of communicating health information delivered via the Internet among Chinese adults [13]. As age increases, so does the reported frustration of using the Internet for health-related information, a factor that could easily be addressed by assessing the ease of use of the websites, and designing effective yet easy to navigate interfaces and layouts. According to the Technology Acceptance Model (TAM), Davis [10] argues that examining the acceptability through perceived usefulness and ease of use could provide understanding of how system design features influence user acceptance [10].

With the rapidly aging population worldwide, especially Asia countries [14], it is imperative that researchers fill the knowledge gap on eHealth communication beyond the U.S. population. While most studies analyze the older population by age groups of 50-64 and 65+, early signs and symptoms of many chronic diseases may begin in those ages of 40 and older [15]. The younger middle age group warrants more attention. Since adults spend more than one-third of time at work, eHealth promotion programs delivered and supported via workplace settings hold promise to influence middle-age adult employees.

This study examined beliefs towards online health communications to assess the potential of worksite eHealth communication programs among middle-age employees before they reach and/or transit into senior or retirement age. The current study aimed to include the younger middle age adults (40-49 years), in addition to the older middle age group (50-64 years). Specifically, this study (1) described the development and examine evidence of reliability and validity of a theory-based eHealth belief inventory (eHealth-BI) aiming to assess the level of perceived benefits (usefulness) and barriers (ease of use) towards online health information; and (2) examined eHealth-BI by key demographic variables (age, gender, education) among middle- and older-age employees in Taiwan. We hypothesized that this theory-based eHealth-BI would show satisfactory reliabilities and sufficient evidence of validities. In addition, participants in their $40 \mathrm{~s}$ would have more favorable eHealth-BI scores than those in their $50 \mathrm{~s}$ and older. Similarly, males and those have higher education levels (college and above) would also have more favorable eHealth-BI scores. Findings from this study would provide needed validation evidence on the new bi-lingual measurement tool to assess eHealth related beliefs. Results can inform health researchers and practitioners better understand the need of system design features for effective eHealth promotion program development among Chinese middle- and older-age adults.

\section{Materials and Methods}

\subsection{Study Participants}

The survey was administered to middle-age employee age $40+$ years in two worksites in Taiwan, a traditional industrial car company and a high-tech manufacturing company. The majority employees in both companies were assembling-line workers. To increase the possibility of developing and piloting worksite eHealth programs in the next stage of the research project, the selection of these sites was mainly based on their long-term commitment and exemplary efforts on employee health and wellness, as well as the history of collaboration with the researchers.

\subsection{Data Collection}

The same data collection procedures were used for both worksites. The research team communicated with the site managers and nurses about the study purpose, consent procedures, and collaboratively discussed ways to identify eligible participants. Site unit leaders and nurses assisted in recruitment, with study purpose and procedures explained during unit meetings. Employees age $40+$ were given the self-administered survey, with assistance provided as needed. Completed surveys were returned to the site nurse. Participants were given a pedometer as a thank-you gift. This study was conducted under the approval of the PI's university institutional human subject office (NO. 2006-10789-4), and informed consent was administered to participating sites as well as each participant before administering the study survey.

\subsection{Measurement}

\subsubsection{Theoretical Foundation of the eHealth Belief Inventory (eHealth-BI)}

This study used a theory-based eHealth Belief Inventory (eHelath-BI) to assess participants' beliefs towards eHealth communication. Technology Acceptance Model (TAM) [10] and related measurements from previous studies conducted in Taiwan [11-12] was used to guide the development of items related to attitudes and beliefs towards eHealth 
communication. The TAM hypothesize that the overall affective attitude toward using a new system is a function of two cognitive beliefs: perceived usefulness (U) and perceived ease of use (EOU). The development of the current eHealth belief inventory incorporated these two important belief constructs from the TAM to help examine the acceptability of eHealth communication and provide understanding of improving utilization through the design of the system. The purpose of the current study is not to prove the utility of the TAM, but rather to incorporate important constructs from this model to understand the underlying mechanisms effecting online health information seeking behavior.

Selected items were adapted and modified from measurement tools from (1) Davis' [10] study, which utilized TAM to assess email acceptance, and was conducted among professional and managerial employees in a large corporation in the U.S.; as well as (2) Yu and Yang's [11] scale measuring web-based learning attitude which was conducted among public health nurses in Taiwan. Items were adapted to measure key concepts of usefulness and ease of use from the original measurements but reworded to fit into the context of eHealth communication.

Preliminary survey items were drafted and subsequently revised according to comments and suggestions from stakeholders, and then piloted the survey among a couple of adult samples in Taiwan prior to the current study. These scale items were developed in English, translated into Chinese, and translated back to English. Items on the two English versions were checked for discrepancy of the meaning. The final eHealth belief inventory (eHealth-BI) thus contained two sub-scales and named as: (1) eHealth-Pros (perceived usefulness of eHealth communication) and (2) eHealth-Cons (perceived ease-of-use towards eHealth communication).

\subsubsection{Process of Developing the eHealth Belief Inventory (eHealth-BI)}

There were three key stages of the eHealth-BI instrument development. The original eHealth-BI developed consisted of 15 items (11 items on eHealth Pros, and 4 items on eHealth_Cons). This preliminary eHealth-BI was tested among a convenience sample of adults in Taiwan $(\mathrm{n}=208)$ [16]. Cronbach alpha showed satisfactory overall reliability (alpha of .89; CITC ranged .37 .70), with the internal consistencies of the two sub-scales also showed satisfactory reliabilities (Cronbach alphas of .91 versus .74 respectively).

In order to make the size of the two sub-scales more equivalent, and to reduce the burden of completing a long scale, efforts were made to shorten this original scale to half of the size. Items measured similar concepts, those with lower CITCs, or increased alphas if item were deleted, were dropped. A three-people panel of experts consisted of expertise of statistics, technology adoption for older adults, and public health communication, were consulted in the process of shortening the original 15 -item eHealth-BI scale. The revised eHealth-BI (short version) consisted of 7 items, with more equivalent size of the two sub-scales: 4 items measures eHealth Pros and 3 items measures eHealth Cons.

This 7-item eHealth-BI was then piloted among another convenience sample of middle-age adults in Taiwan $(n=151)$ [17]. Data showed the reliabilities of the eHealth-BI (short version) had satisfactory and improved internal consistencies, with Cronbach alphas of 0.94 for eHealth_Pros (4-items) and 0.78 for eHealth_Cons (3-items). The current study used this 7-item short version of this previously tested eHealth-BI scale to validate and confirm the scale structure for use to assess beliefs towards eHealth communication among participating employees in Taiwan.

\subsection{Data Analysis}

Descriptive statistics, item-total correlation, and Cronbach's alpha coefficients were calculated for each eHealth-BI sub-scale to evaluate internal consistencies among participating middle-age working adults in Taiwan. The reliabilities and scale means were calculated using Cronbach alpha for each of the age group. Confirmatory factor analysis was then applied to examine the proposed two-factor model among study participants. The purpose of this process was to determine whether or not there was sufficient empirical evidence that the model, as specified, was a viable representation of the true relationships between observed and latent variables [18]. Judgments about model fit were made jointly by assessing the ratio of chi-square to degrees of freedom $\left(\mathrm{X}^{2} / \mathrm{df}\right)$, root mean square error of approximate (RMSEA), incremental fit index (IFI), and comparative fit index (CFI). The criteria used to determine if the model fits the data showed RMSEA no more than .08 [19], and values of IFI, and CFI at least .90 [20]. Factor loadings were considered statistically significant if the ratio of the factor loading to its standard error was greater than 1.96 or less than -1.96 [21]. The structure of factor loadings was provided in Figure 1.

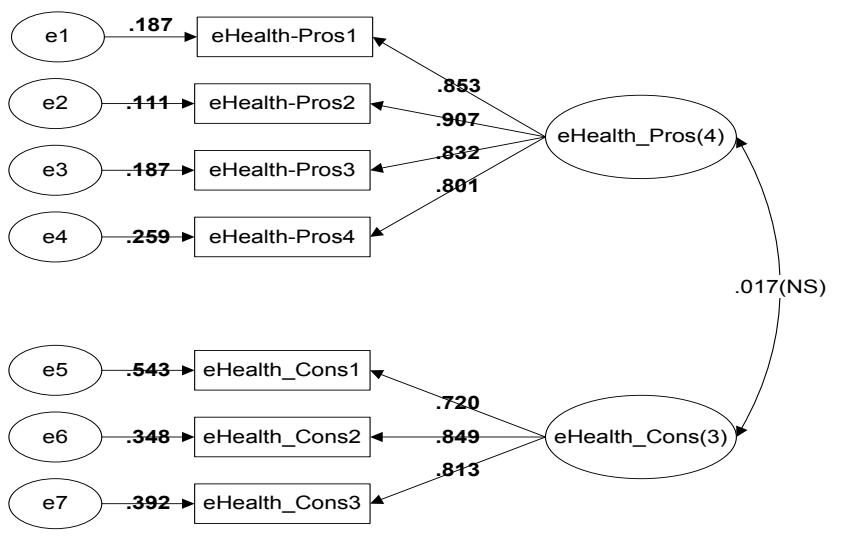

Model fit Index ( $=529)$ : Chi $/ \mathrm{df}=49.02 / 13=3.77 ;$ RMSEA= $072(.02 ; .095)$; $\mathrm{NFI}=.98 ; \mathrm{TLI}=.97 ; \mathrm{CFI}=.98 ; \mathrm{IFI}=.98 ; \mathrm{GFI}=.98$

Note: SMC (squared multiple correlations) ranged: .519 .824

Figure 1. The structure and item loadings of the eHealth-BI (7-items; short version)

In addition, t-tests were used to compare scores of the 
eHealth-BI sub-scales by different age, gender, and education groups to examine beliefs towards eHealth communication among individuals with different demographic characteristics.

\section{Results}

\subsection{Demographics of Participants}

A total of 533 middle-age employees participated in this study, with about half from each of the two study workplaces. Majority was married (87.3\%), and the mean age was 46.21 $(\mathrm{SD}=5.01)$ years. Nearly three-fourth of the participants aged between $40-49$ years. The age distributions are proportion to that of the respective participating companies. There was no significant difference on gender between the two age groups. However, adult age 50-64 years was less likely to have college education $(25.0 \%$ versus $50.9 \% ; \quad \mathrm{p}<.001)$. Participants from the car company also tended to be a few years older (47.9 vs. 44.7 years old; $\mathrm{p}<.001$ ). Overall, about $40.6 \%$ of the participating employees reported having a cancer history within their family members or relatives. However, the majority perceive their own risks of getting cancer were lower or about the same $(91.5 \%)$.

\subsection{Validation of the eHealth Belief Inventory (eHealth-BI)}

The 7-item short version of the eHealth Belief Inventory (eHealth-BI) was used to assess beliefs towards eHealth communication. The reliabilities of the eHealth-Pros (4-items) measured by Cronbach alphas were .89 (CITC ranged $.723 \sim .805 ; \mathrm{n}=387$ ) among the $40-49$ years age group and .94 (CITC ranged .820 .901; $\mathrm{n}=146$ ) among the 50-64 years age group, indicating satisfactory internal consistencies among items within each sub-scale. Cronbach alphas were also satisfactory for the eHealth-Cons (3-items) with alphas of .84 (CITC ranged .638 .733; $\mathrm{n}=387$ ) among the 40-49 years group and also .84 (CITC ranged .687 .738; $\mathrm{n}=146$ ) among the 50-64 years group (see Table 1). Table 1 described the eHealth-BI (7 items), with Chinese-English side-by-side translations. Given satisfactory reliabilities, the confirmatory factor analysis (CFA) was then applied to test the 7-item eHealth-BI two-factor model (Fig 1). Confirmatory factor analysis showed that the eHealth-BI items were loaded in a way consistent with the 2 priori-specified constructs among participating middle-age working adults. Model fit index obtained from Amos output showed that items were loaded consistently and significantly with these two eHealth-BI sub-scales with good model fits (RMSEA $=.072$ [.020; .095]; NFI=.98; TLI=.97; CFI=.98; $\mathrm{IFI}=.98 ; \mathrm{GFI}=.98 ; \mathrm{n}=529$ ). Data provided empirical evidence that the model, as specified, represent sufficient true relationships between observed variables and the underlying theoretical constructs (i.e. perceived benefits eHealth-Pros and perceived barriers eHealth-Cons).

\section{3. eHealth-BI by Age, Gender, and Education}

Analyses showed that there was no significant difference on the mean scores of the eHealth-BI scales between age groups. The overall scale means (7-item) indicated positive beliefs towards eHealth communication in both age groups. Participants in general had high endorsement on the benefits or usefulness of eHealth communication (eHealth-Pros); yet at the same time, feel medium level of barriers on the ease of use regarding online health information (eHealth-Cons). Data showed that males were more likely to perceive higher level of benefits towards eHealth communication $\left(\mathrm{t}_{(270.8)}=-2.62 ; \mathrm{p}=.009\right)$, although the perceived barriers showed no statistical difference between males and females. In addition, individuals with college education or higher were more likely to perceive higher benefits and lower barriers towards eHealth communication (Table2). 
Table 1. Psychometric Information for the eHealth-BI by age groups

\begin{tabular}{|c|c|c|c|c|}
\hline Scale & $\begin{array}{c}\text { Item description } \\
\text { Age } 1 \text { ( } 40-49 \text { years); } \\
\text { Age 2 (50-64 years) (Italic) }\end{array}$ & Mean (SD) & CITC & $\begin{array}{c}\text { Alpha if } \\
\text { item } \\
\text { deleted } \\
\end{array}$ \\
\hline $\begin{array}{l}\text { eHealth-Pros } \\
\text { (perceived } \\
\text { usefulness) }\end{array}$ & $\begin{array}{l}\text { eHealth-Pros (Age 40-49 years) (Cronbach Alpha }[4-i t e m]=.89 ; \mathrm{n}=387) \\
\text { eHealth-Pros (Age 50-64 years) (Cronbach Alpha }[4-i t e m]=.94 ; n=146)\end{array}$ & & & \\
\hline eHealth-Pros_1 & $\begin{array}{l}\text { Using web-based learning for health information communication enables me to learn } \\
\text { more than would otherwise be possible. }\end{array}$ & $\begin{array}{l}3.91(.75) \\
3.79(1.01)\end{array}$ & $\begin{array}{l}.741 \\
.862\end{array}$ & 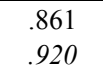 \\
\hline eHealth-Pros_2 & $\begin{array}{l}\text { Using web-based learning for health information enhances the effectiveness of } \\
\text { communication. }\end{array}$ & $\begin{array}{l}3.90(.74) \\
3.80(.92)\end{array}$ & $\begin{array}{l}.805 \\
.901\end{array}$ & .837 \\
\hline eHealth-Pros_3 & Using web-based learning enables me to learn health information more quickly. & $\begin{array}{l}3.99(.70) \\
3.93(.97) \\
\end{array}$ & $\begin{array}{l}.757 \\
.848\end{array}$ & $\begin{array}{l}.856 \\
.924\end{array}$ \\
\hline eHealth-Pros_4 & Using web-based learning enhances the quality of health communication. & $\begin{array}{l}3.82(.80) \\
3.72(.97) \\
\end{array}$ & $\begin{array}{l}.723 \\
.820\end{array}$ & .870 \\
\hline $\begin{array}{l}\text { eHealth-Cons } \\
\text { (perceived } \\
\text { ease-of-ues) } \\
\end{array}$ & $\begin{array}{l}\text { eHealth-Cons (Age 40-49 years) (Cronbach Alpha }[3-\text { item }]=.84 ; \mathrm{n}=385) \\
\text { eHealth-Cons (Age 50-64 years) (Cronbach Alpha }[3-\text { item }]=.84 ; n=144)\end{array}$ & & & \\
\hline eHealth-Cons_1 & I find health info communicated via web-based channel cumbersome to use. & $\begin{array}{l}2.91(1.05) \\
2.98(1.10)\end{array}$ & .638 & $\begin{array}{l}.828 \\
.793 \\
\end{array}$ \\
\hline eHealth-Cons_2 & I find it takes a lot of effort to become skillful to use the Internet. & $\begin{array}{l}2.73(1.08) \\
3.10(1.16)\end{array}$ & $\begin{array}{l}.733 \\
.738\end{array}$ & $\begin{array}{l}.736 \\
.744\end{array}$ \\
\hline eHealth-Cons_3 & Learning via the Internet will lower learning effect. & $\begin{array}{l}2.70(1.07) \\
2.78(1.10) \\
\end{array}$ & $\begin{array}{l}.723 \\
.687 \\
\end{array}$ & $\begin{array}{l}.747 \\
.794 \\
\end{array}$ \\
\hline
\end{tabular}

Table 2. eHealth-BI by age, gender, and education groups

\begin{tabular}{|c|c|c|c|}
\hline & $\begin{array}{l}\text { Age ( } 40-49 \text { years) } \\
\text { Mean (SD) }\end{array}$ & $\begin{array}{l}\text { Age (50-64 years) } \\
\text { Mean (SD) }\end{array}$ & P-value \\
\hline eHealth-BI (7) & $23.96(3.84)$ & $24.10(4.51)$ & NS \\
\hline eHealth-Pros (4) & $15.62(2.58)$ & $15.24(3.57)$ & NS \\
\hline \multirow[t]{2}{*}{ eHealth-Cons (3) } & $8.34(2.78)$ & $8.85(2.93)$ & NS \\
\hline & $\begin{array}{l}\text { Gender (Male) } \\
\text { Mean (SD) }\end{array}$ & $\begin{array}{l}\text { Gender (Female) } \\
\text { Mean (SD) }\end{array}$ & P-value \\
\hline eHealth-BI (7) & $24.15(3.87)$ & $23.65(4.37)$ & NS \\
\hline eHealth-Pros (4) & $15.75(2.72)$ & $15.01(3.16)$ & $\mathrm{t}_{(270.8)}=-2.62 ; \mathrm{p}=.009$ \\
\hline \multirow[t]{2}{*}{ eHealth-Cons (3) } & $8.39(2.84)$ & $8.66(2.78)$ & NS \\
\hline & $\begin{array}{c}\text { Education }<\text { College } \\
\text { Mean (SD) } \\
\end{array}$ & $\begin{array}{c}\text { Education }>=\text { College } \\
\text { Mean (SD) }\end{array}$ & P-value \\
\hline eHealth-BI (7) & $24.34(4.20)$ & $23.59(3.77)$ & $\mathrm{t}_{(521)}=2.13 ; \mathrm{p}=.03$ \\
\hline eHealth-Pros (4) & $15.29(3.03)$ & $15.83(2.66)$ & $\mathrm{t}_{(516.3)}=-2.16 ; \mathrm{p}=.03$ \\
\hline eHealth-Cons (3) & $9.05(2.73)$ & $7.77(2.80)$ & $\mathrm{t}_{(521)}=5.29 ; \mathrm{p}<.001 * *$ \\
\hline
\end{tabular}

Notes: NS = non-significant; $* *=\mathrm{p}<.001$

Overall (all $n=529)$ : mean (SD): eHealth-BI $(7)=24.00$ (4.02)

eHealth-BI Pros (4)=15.52 (2.88); eHealth-BI Cons (3)=8.48 (2.83)

\section{Discussion}

The current study data showed this theory-based eHealth-BI instrument had satisfactory reliabilities and validities. This validated tool provided new opportunities for health and communication researchers to assess beliefs on usefulness and ease-of-use towards using Internet for health communication. The instrument has been carefully developed and tested among a number of adult samples in Taiwan. Its bi-lingual feature enables researchers and practitioners to reach the Chinese-speaking populations. The study has implication on using the eHealth-BI tool for targeted eHealth communication interventions.

Overall, participants viewed positively towards e-Health communication. Although younger middle-age participants perceived a little higher benefits and lower barriers than older middle-age workers, the differences were not statistically significant. This finding was a little unexpected as we had hypothesized that those in their 40s might still have more favorable eHealth communication beliefs than 
those in their 50s and older. Previous studies have not had consistent observations on this relationship [2-3, 22]. The overall high endorsement on the benefits of eHealth communication observed in the current study suggested age difference might be not as important factor on how one perceives eHealth communication, comparing with other demographic characteristics.

Current data indicated males perceive higher level of benefits towards eHealth communication. This is consistent with our hypothesis and existing findings that males were more likely to report positive online health seeking experience than women [22]. It should be noted that the perceived barriers or ease-of-use, however, were similar between males and females. Participants in general endorsed medium level of barriers of communications via the Internet. The current data suggest that barriers to technology or Internet experience cannot be overlooked even in the case of high endorsement on the utility of eHealth communication. For middle- and older-age adults, regardless of gender, user friendly and senior-oriented Internet interface are important to increase acceptability and utilization.

Our finding also showed that those with college education perceived significantly higher benefits and lower barriers towards eHealth communication. This is also consistent with our hypothesis and existing findings [2].

In summary, this study provides empirical data describing the reliability and validity of the eHealth-BI instrument measuring eHealth related beliefs among Chinese adults. This bi-lingual eHealth-BI instrument provides researchers and health professionals an important tool to measure beliefs towards eHealth communication for better understanding of system design needs. Data suggest, regardless of age differences, senior-friendly user interface and appropriate literacy level might warrant particular attention. Results have implications on using this eHealth-BI tool for assessing beliefs and designing effective eHealth communication interventions among middle- and older-age working adults.

\section{REFERENCES}

[1] Neuhauser, L., \& Kreps, G.L. (2010). eHealth communication and behavior change: promise and performance. Social Semiotics, 20(1), 9-27. DOI:10.1080/10 350330903438386 .

[2] Fox, S. (2006). Online health search 2006. Pew Internet and American Life Project. Online available from : http://www.pewinternet.org/Reports/2006/Online-Health-Se arch-2006/03-113-Million-Internet-Users-Seek-Health-Infor mation-Online.aspx?view=all.

[3] Ybarra, M., Suman, M. (2008). Reasons, assessments and actions taken: sex and age differences in uses of Internet health information. Health Education Research, 23 (3), $512-521$

[4] Madden, M. (2010). Older adults and social media. Pew Internet and American Life Project. Online available from:
http://www.pewinternet.org/Reports/2010/Older-Adults-andSocial-Media/Report.aspx?view=all.

[5] Madden, M., \& Zickuhr, K. (2011). Health information online. Pew Internet and American Life Project. Online available: http://pewinternet.org/Reports/2011/Social-Networking-Sites .aspx.

[6] Fox, S, \& Purcell, K. (2010). Chronic disease and the Internet. Pew Internet and American Life Project. [Cited 2 October 2012.] Available from URL: http://www.pewinternet.org/Re ports/2010/Chronic-Disease/Part-3.aspx?view=all

[7] Huntington, P., Nicholas, D., Homewood, J., Polydoratou, R., Gunter, b., Russell, C., \& Withey, R. (2004). The general public's use of (and attitudes towards) interactive, personal digital health information and advisory services, Journal of Documentation, 60(3), 245-265.

[8] Health Information National Trends Survey. (2010). Brief 16: Trends in Cancer Information Seeking. Online available from: http://hints.cancer.gov/brief_16.aspx.

[9] Iverson SA, Howard KB, \& Penney BK. (2008). Impact of Internet use on health-related behaviors and the patient-physician relationship: a survey-based study and review. The Journal of the American Osteopathic Association,108(12), 699-711.

[10] Davis, F.G. (1993). User acceptance of information technology: system characteristics, user perceptions and behavioral impacts. International Journal of Man-Machine Studies, 38, 475-487.

[11] Yu, S. \& Yang, K.F. (2006). Attitudes toward Web-based distance learning among public health nurses in Taiwan: a questionnaire survey. International Journal of Nursing Studies, 43(6), 767-74.

[12] Chen, I. J., Yang, K.F., Tang, F.I., Huang, C.H., \& Yu, S. (2008). Applying the technology acceptance model to explore public health nurses' intentions towards web-based learning: A cross-sectional questionnaire survey. International Journal of Nursing Studies, 45, 869-878.

[13] Hou, S., Hsiao, T.J., \& Hou, P.H. (2012). Online health information (OHI) utilization among employees age $40+$. International Electronic Journal of Health Education, 15, 99-111.

[14] Chinese Academy of Social Sciences, Indian National Science Academy; Indonesian Academy of Sciences; National Research Council of the U.S. National academies; \& Science Council of Japan. (2011). Preparing for the challenges of population aging in Asia - strengthening the scientific basis of policy development. Washington (DC): National Academies Press (US).

[15] American Academy of Ophthalmology (AAO). (n.d.). Get screened at 40. Online available from: http://www.geteyesm art.org/eyesmart/living/screening.cfm

[16] Hou, S. (2009, Aug.). Developing and validating an eHealth Belief Inventory (eHealth-BI) among Chinese adults. Poster presented at the $3^{\text {rd }}$ National Conference on Health Communication, Marketing and Media, Atlanta, GA.

[17] Hou, S., Lui, L., \& Wen, M.J. (2010). Internet utilization and beliefs toward eHealth communication among Chinese middle-age adults from a community college in Taiwan. Poster session presented at the $138^{\text {th }}$ Annual Meeting of 
APHA, Denver, CO.

[18] Mueller R.O. (1996). Basic principles of structural equation modeling: An introduction to LISREL and EQS. New York: Springer.

[19] Raykov T. (2001). Approximation confidence interval for difference in fit to structural equation model. Structural Equation Modeling, 8, 458-469.

[20] Byrne B.M. (1998). Structural Equation Modeling with LISREL, PRELIS, and SIMPLIS: Basic concept, applications, and programming. Mahwah, NJ: Lawrence Erlbaum Associates.

[21] Joreskog K.G., \& Sorbom D. (1996). LISREL 8: User's reference guide. Chicago, IL: Scientific Software Internation al, Inc.

[22] Hou, S., Hsiao, T.J., \& Hou, P.H. (2012). Online health information (OHI) utilization among employees age $40+$. International Electronic Journal of Health Education, 15, 99-111. 